\title{
THREE CASES OF INTRACRANIAL COMPLICATIONS ORIGINATING IN THE EAR.
}

\author{
By Dr. E. J. Mourl, \\ Professor of Otology in the Faculty of Medicine of Bordeaux. \\ (Translated by 1)r. Dexdis Graxt.)
}

CEREBRAI complications of otitic origin are far from being uncommon either in France or abroad, but while in our country they generally constitute post-mortem discoveries, in other countries, on the other handand particularly within the last few years-surgical intervention has been carried out during the coursc of these complications with the object of suppressing them and consequently of curing the patient. The cases of encephalic abscesses of otitic origin, as well as those of thrombosis of the sinus, or even of suppurative phlebitis, propagated in the jugular vein, which have been operated on with success are extremely numerous in foreign medical literaturc. In France, on the contrary, it is as much as one can say that a few operators have attempted to interfere in this class of casc. Our confrive, Dr. Lannois, reported, last year, a case in which operation on an otitic absceso was attempted, but evacuation was not found possible.

M. Broca has recently communicated to the Surgical Society of Pars a certain number of cases of different cerebral complications treated surgically, being relieved and curcd by this intervention. In a large number of them this surgeon always follows the auricular route in openin: the skull, because, as he says with truth, in this way one passes through the initial lesions which are known towards the secondary complications to which the local lesion conducts the operator.

At Bordeaux, Prof. Lannelongue has had the opportunity of opening a sinus in order to remove a clot which had given rise to the classical symptoms. I have had myself to interfere three times within the present year in cases of intracranial complications consecutive to aural lesions. These are the cases which I am about to narrate ; they are all interesting, because each conveys some instruction, either from the point of view of the diagnosis of the lesion itself, or from the results obtained by intervention.

If theoretically it secms easy to recognize the different intracranial complications of otitic origin, it is far from being so in practice; thus extradural abscess, meningitis, and encephalic abscess often give rise to clinical symptoms which resemble each other exactly. Very often, indeed, it is almost by the absence of symptoms that one comes to be able to make the diagnosis.

of all the cerebral complications, meningitis is perhaps the one of which the lesions are the most easy to recognize, because they are generally diffuse, and bring about external signs which are sufficiently clear

3 Read lefore the French Larywological and Otolocical So:icts, Aprol. 1807 . 
and haracteristi: ditruse headache, vomtins. strabismus, contracture, paralysis, ctc.). It is sufficieni to read the treatises on surgery, and in particular the recent works of Broca and Maubrac, or of Chipault, to see the uncertainty of the symptoms which appear in abscess or phlebitis of the sinus, more especially as those two lesions are found combined to:ether or even exist along with aural meningitis, extradural abscess, etc. $F$ urther, in certain cases the changes in the ear or in the mastoid process appear to be sufficient to explain, at least in part, the symptoms observed, and, consequently, to divert the observer from the idea of a deeper complication being present. Thus it happens that being encouraged by previous successes, one may limit oncsclf to simple intervention in the region of the middle ear or of those accessory cavities, sometimes even as far as the dura mater, without searching more deeply in the interior of the skull or the sinus for a lesion capable of explaining the clinical phenomenat.

We are all the more justified in acting thu because very often fever or unilateral headache are the only signs which lead us to think of the presence of one or the other of the complications of aural disease. 1 make no reference to the changes found in the fundus of the eye, double or single neuritis, as these signs are often absent in cases of localized cerebral lesions, but, on the other hand, often exist in certain diffused inflammations, such as meningitis, in which operative interference is uscless.

There is no doubt that when intracranial surisery for the complications of ntitis comes to be practised more frequently among us, as it is abroad. clinical experience will lead us to recosnize some, if not all, of these complications and their possible combinations, so that we shall come to know in which cases it is necessary to stop before opening the brain; and those, on the other hand, in which it is our duty to so more deeply, in spite of the existence of morbid changes found in the more superficial parts.

The three cases which I am about to narrate are intcresting from thes point of view. I will describe them in the chronological order in which I have had the opportunity of observing them.

Case I. Suppurative Itidian otitis of the Left Ear, Adenoid lisehations. Cessation of the Discharge after the Removal of the Vegetations. There months later Measles and Recurrence of Suppuration in the Ear. Alternations of Cessation and Recurrence of the Otorrha'a. Meningitio Phenomena eight montlis after the Occurrence of Measles. Mastoid Piriostitis. Incision; Bare Bonc. Trephining four days later. Large Abscesses and Masses of Granulations between the Dura Mater and the Cranial Bone. Recovery.

(Reported by Dr. BRinuel, Assistant in the Otological Clinic, etc.)

T. II., aged five years, suffered from oterrhear of the left ear of several months' duratiun, kept up by the presence of a large mass of adenoid regetations in the nass-pharyns. It is now a year since the vegetations were removed, and within a fer days after that operation the discharge of pas came to an end, the chilel in a few months becoming rony and plump. IJowever, he wan attacked with meanles 
three months after the operation, and his otorrhoa returned, but it yielded in a few weeks to simple injections of boric acid. At that time the membrane healed up completely and the hearing became excellent.

From the month of April to that of December, 1896, he had from time to time attacks of pain in the ear, and a slight clischarge from the meatus, but his relatives did not take much notice of these incidents and sought no advice con. cerning them. Towards the middle of December, however, the child was suddenly attacked with severe meningitic symptoms, which made it necessary for him to be kept in bed for eight hours, causing great anxiety for his life. He recovered, however, in a very short time, the improvement starting from the day that the purulent discharge reappeared in the ear. A few days later a swelling appeared in the region of the mastoid process, and particularly in the peri-mastuid tissue. There was some rise of temperature at night; the auricle was projected forward, and it was tender on pressure, as was also the tip of the mastoid process. The appearance suggested a simple mastoid periostitis, and under bromide of ethyl the actual cautery was applied to several spots on the mastoid. From this time the swelling hecame less diffuse, it narrowed itself, and in two days presented the appearance of a rounded prominence, situated two and a half or three centimetres from behind the auricular attachment at the level of the lower third of the mastidid process, immediately behind this. At the most prominent point there was distinct but deep fluctuation. An incision was made on December 24 th, and pus was evacuated from below the periosteum. It was thick, white, and laudable. A grooved director passed into the bottom of the wound was found to penetrate the bone, so that the presence of caries was assured. Drainage and antiseptic dressing were the only further treatment carried out for the time. After two days the pus ceased, but there still continued a slight rise of temperature at night. During the day the appetite was good, the child was in excellent spirits; but in the evening he experienced a slight rigor, followed by a fecling of heat and gencral agitation. On the 28th the child was brought to the clinic in the same state, and it was decided to talie him into the children's hospital for the purpose of operation.

The operation was performed on the 3 oth of December. The child wan in gond spirits playing with his toys, and the first idea was to limit all intervention to a simple enlargement of the wound under chloroform, and scrape the carious bone. An incision from five to six centimetres long was made, with its axis parallel to the auricular fold, but including the former wound, and the periosteum was pushed backwards and forwards. There was then found in the retronastoid groove, at the junction of the inferior and middle thirds of the process, a small fungating point, which was the orifice of a fistulous track, through which a probe could be passed into the cranial cavity. Guarded by Stacke's protector, this fistulia was enlarged by means of the gouge and mallet, and a quantity of pus of the same sort as that described above was evacuated. A large cavity filled with granulations, covering the lateral sinus, and rising and falling with the pulse, was thus laid open. The granulations were scraped away. The wall of the sinus and the internal surface of the cranial wall were touched with a ten per cent. solution of chloride of zinc. The opening extended to the latter extremity of the mastoid process, of which quite a third was removed, so that the antrum opened freely into the cranial cavity. A large drainage tube was introduced into the wound and liept there by means of a suture, the incision being closed above and below the drain by means of stitches. A large dry dressing was applied. On the evening of the operation the temperature was $38 \cdot 2$. Next day the temperature was, in the morning, 375 ; in the evening, $38 \cdot 5$; and on the following morning, 37.8 . On the and of January, 1897, the child was pretty well, the morning temperature being $37^{\circ} 4$, and the 


\section{Rhinology, and Otology.}

evening one $38 \cdot \mathrm{I}$. The dressing was changed, and a small quantity of pus could be washed out through the drainage tube. Three or four of the cautery spots had suppurated and infected one of the stitches. Two stitches were removed. The body was covered with an urticarial rash, attributable to the iodoform. This drug was therefore omitted, and salol used in its place. Next day the urticaries had disappeared ; the temperature was, in the morning, 37.6 , and in the evening, $57^{\circ}$; on the $4^{\text {th }}$ of January, $37^{\circ} 4$ and $37^{\circ} 6$. The dressing was then changed; one of the cauterized spots was suppurating; the rest of the stitches were removed, the wound being found to have united. The child had been up during the last two days; the tongue was clean, the appetite good, and the patient had got tired of leing in the hospital. Very little pus could be washed out, and the salol dressing was re-applied. From this time there was no more furrishness. The drescing was changed twice a week, and the pus diminished rapidly in quantity.

On January 17 th the drainage tule was withdrawn, after having been gradually shortened. The child had greatly improved in condition, and the wound was healing rapidly. Rapid improvement trok place. A few granulations had to be canterized with nitrate of silver, the original track was swabbed with chloride of zinc, and on the and of February no more lare lone could be felt with the probe. On the roth of February the granulating track was cauterized with chromic acid. On the I 5 th there remained nothing but a dry crust on the orifice of the drain track. There was no tenderness on pressure, the child was in good health, and subseruently became perfectly well.

In the second case the patient was a woman, from whose cadaver anatomical preparations were removed at the post-mortem examination, and demonstrated before the Anatomical and Physiological Society of Bordcaux by Dr. Bosquet, who at the same time reported the clinical history of the case up to the time of my intervention.

Case 2. Mastoid Osteo-Periostitis. Extradural Abscess and Cerebral Abscess. Petro-Mastoid Evacuation. Death. Autopsy.

Dr. BOsqueT's account of the case is as follows:-

I have the honour of exhibiting before the Anatomical Society the brain of a patient who died in Dr. Chambrelent's ward in the part set aside for accouchements. There is an abscess in the left sphenoidal lobe consecutive to median otitis. The patient entered the IIopital St. André on the Ioth of last month, accompanied by people who were unable to give any particulars concerning her; she was herself incapable of replying to any questions, and was in a semi-comatose condition : she was continually delirious, without fever, and had nearly completed the ninth month of gestation. In the ward her delirium became violent and ambulatory ; she was thought to be affected with puerperal mania. On the 13 th of March labour hegan and the patient was sent to the maternity department, when a slight degree of albuminuria was discovered, and it was supposed that the delirium was uramic. The labour was rapidly terminated by means of the forceps applied as soon as the degree of dilatation permitted. The child was alive and well formed, and is at present in perfect condition in the Children's Hospital.

On the 15 th of March the patient was removed to the isolation ward on accoun: of the delirium, which prevented her from being allowed to remain among the other maternity patients. She had there some degree of fever, and on the evening of the 16 th the temperature was $39^{\circ} 6^{\prime \prime}$; there was constipation, but no vomiting. The pulse was rapid, there was a calm delirium, and slight contraction of the muscles of the nape of the neck.

The diagnosis was held in slopense, when, on the I 8 th if Varch, there was 
noticen on the patient ear sume stain of pus insuing from the righlt extemal auditory meatus. It was then elicited from the relations that at ten years of age she had suffered from suppurative otitis, which had led to the complete loss of the hearing of the right ear, and that from time to time she had had pain in the ear : also that a weck before her entry into the hospital, while she appeared in perfect health, she was suddenly seized with pain in this ear, radiating over the temporat fossa of the same sile and accompanied by delirium, the persistence of which had led them (1) bring the patient to the hospital.

The presence of pus in the ear and the former history of the patient then suggested the supposition that the various symptoms which she presented were due (1) a lesion, the point of origin of which was the ear.

Dr. Noure was called to the case by Dr. Chambrelent on the rgth of March, when he found a collection of pus and a seruestrum in the ear. There was at the level of the root of the rygomatic arch a subcutaneous purulent collection which appeared to come from the ear. Pressure on the mastoid procesy caused great pain. There was obviouly a purulent median otitis, but the question arose as to whether the lesion was confined to the ear. There were no clear signs of atseess of the brain or of meningitis; simply headache, deirium, an oscillating temperature, and uptic neuritic, more marked in the right eye, as cunfirmed ly Dr. Iromaget.

In. Noure decided to operate, and on the 20 th March performed petro-mastoit evacuation. A purulent track was found leading from the vault of the carity of the tympanum; it was followed up and enlarged, and it led through the middle cerebral fowa to an cxtradural aliscens. It this point the dura mater over the extent of an area the size of sixpence was reddish and devoid of expansional movement, while all around it was attached and healthy in appearance.

It was curcted and punctured, but the bistoury, inserted to the dephly of a centimètre and a half, did not lead to any escape of pus. The operation was cont pletel ly tamponning with salol gratue and suturing the soft parts.

The delirium and fever persisted, and the patient died on the 2 sot of March. thirty hour; after the operation.

It the autopsy, which was male on the morning of the $22 \mathrm{nd}$, there was fomd an abscess of the brain continuous with the lesion in the ear; the dura matcr, though granular at the part inclicated, was not perforated. The site of the puncture made with the bistoury could be traced, and the absence of escape of pus was to be explained by the formation of false membranes which increased the thickness of the meninges, while in order to reach the pus the instrumant would have had to be inserted to a depth of from one to two centimetres. Over the second and third temporal convolutions, for an area of five centimetres, the cortical substance was compressed and greyish in colour ; it gave way when the pia mater, which was adherent to it, was lifted, and the cavity of the abscess was thus laid open. There was free continuity with the lateral ventricle.

On transverse section it was found that the third and fourth ventricles had escaped, and that the abscess, having a length of five centimetres and a height of three, was of such a depth as to reach from the cortical surface to the lateral ventricle. The purulent contents of the abscess were greyish, but a close examination was not made, and there was found at the same time thrombocis of the right lateral sinus.

I ask the opinion of the Society as to the probable age of this abscess. The woman was delivered on the 12 th, and died on the 21 st; the abscess was probably in exi,tence before the confinement, and did not prevent the period of gestation continuing to the normal term, 
It i; easy to recognize that in this case 1 interfered too long after the commencement of the disease for me to judge of the efficacy of $m y$ first operation, and to perform a second one in the way I had proposed. Erents followed each other with such rapidity that the patient unfortunatcly succumbed before I was able to reach the interior of the skull, in order to search for a lesion capable of explaining the persistence of the clinical symptoms after the opening of the antrum and the evacuation of the cxtradural abscess. It was necessary in addition to take into account the puerperal condition of the patient, having gone through the process of parturition five days before, and consequently being highly susceptible to infection subsequent to the birth of her child. Before we had time to eliminate this important element in our hypothesis the patient died, from the sudden bursting of an enormous cerebral abscess into the ventricles. Even if I had at the time of the first operation found pus in the brain and evacuated it from this large cavity, the patient would probably nevertheless have succumbed, because the surrounding cerebral substance was in such a state of softening that her recovery was not even to be thought of.

At the same time this case is interesting from the point of view of the course of the symptoms and of the fact that the ear had allowed itself to be completely forgotten up to the moment of parturition. In fact, during the inflammatory period all sorts of lesions were thought of, such as mental or other troubles, but there was no idea of any possible complications arising in the ear. It must be admitted, at the same time, that symptoms of mental alienation during the course of cerebral abscess are so rare that the car might very well have escaped attention even in their presence. In addition, the suppuration from the ear was extremely slight, as is usual in cases of complication, and there was only the fotor to awaken the suspicion of the medical attendant.

The case is interesting on account of the slow, insidious development of this cnormous abscess, by the hyperthermia and the acceleration of the pulse, instead of the hyperthermia and slowness of heart's action which is often observed in these cases. Ayain, although there existed an old thrombosis of the superficial cerebral veins, and, in particular, of the lateral sinus, it was obstructed by an orsanized clot, of which the limit were not noted at the time of autopsy. We found no external sign which could lead us to think of the existence of this complication. This point is classical, because in most cases cerebral abscesses of the temporosphenoidal lobe are complicated with phlebitis, or at least with thrombosis of the lateral sinus. Further, whenever one sees an alsscess in the course. of an intracranial operation, the sinus ought always to be exposed, in order that its condition may be tested. These are the anatomo-pathological pieces of information which it is necessary to possess, because in general it is impossible to establish one's diagnosis entirely on the clinical symptoms, and in a case of this kind it is necessary to recommend the friends to allow of an operation.

The third example which I had the opportunity of observing at the same time as the woman of whom I have just spoken occurred in a young child, whose clinical history is equally interesting because it presented sertan diagnostic difficulties and led to the postponement of interference. 


\section{Case 3. Measles. Suppurative Median Otitis. Phlebitis of the Lateral Sinus. Petro-Mastoid Evacuation. Opening of the Sinus. Death.}

M. X., aged thirty months, had in the previous January had an ordinary attack of measles, which was complicated with broncho-pneumonia, threatening the child's life. He had scarcely recovered from this complication when he was attacked with pains in the ear, followed soon after by a discharge of pus, which did not take long to come to a termination, and give rise to the idea that a complete cure had taken place. However, the fever persisted, reaching the height of $39 \frac{1}{2}^{\circ}$, and even at times to $40^{\circ}$. In the presence of these symptoms the practitioner in attendance called into consultation Prof. I'iéchaud, of Bordeaux, who, after having examined the child and heard the account of its complications, thought that the condition of the ear might be the cause of the persistence of the fever, in spite of the complete cessation of discharge. I was then called in to see the little patient on the 2oth of March. At my first examination I found the child fairly cheerful, free from any sign of pain on pressure either on the mastoid process or in any other part of the skull; but the medical attendant told me that two years previously he had had a somewhat violent rigor, accompanied by a rise of temperature to the height of $40^{\circ}$. From that time the febrile symptoms persisted with considerable intensity, but there were no further rigors, and within twenty-four hours the child appeared to have improved considerably. I examined the ear and found the tympanum red, and bulging strongly outwards; the neck was quite free from rigidity, there were no ocular symptoms, nor any other general disturbances. I then proposed to make a free opening through the membrana tympani, to give exit to the liquid which was certainly confined in the cavity. This operation was performed under chloroform. I effected a wide myringotomy, which was followed by the expulsion of a certain quantity of thick non-foetid pus. It was decided then to wait for forty-eight hours in order to judge of the effect of this intervention, and if at the end of that time the fever had not disappeared, a more extensive operation, namely, the free opening of the mastoid process, was to be carried out.

Two days later, the fever symptoms having persisted with the same intensity, I performed the operation of which I have spoken, with the assistance of Prof. Piéchaud and the medical attendant. We found the bone hard, but inflamed, bleeding easily and traversed by emissary veins, which during the operation emitted such a considerable quantity of blood as to render the proceedings somewhat difficult. The mastoid antrum was absolutely full of pus and granulations. The surrounding bone was the seat of a slight osteitis, and was carefully curetted and swabbed with a ten per cent. solution of chloride of zinc. The auricle was re-united by means of stitches, and drainage was carried out through the meatus. The cartilaginous part having been slit up, and the posterior osseous wall resected, all went well for forty-eight hours, but, nevertheless, the febrile phenomena persisted with almost the same intensity as before. Under these circumstances I explained to the family my fear that there was a deeper complication, which, if it did not affect the meninges, involved the surroundings of the sinus, or the sinus itself-in short, I spoke of pyremia of sinusal origin. In spite of this thiy legged me to endeavour to find in the dressing some sign of suppuration which would explain the febrile phenomena. Forty-eight hours after I found the wound in
perfect condition, apparently tending to close. Two days later, the symptms persisting continuously, I again undid the dressing, and this time I found the antrum full of pus, and the stitches suppurating. I opened the wound freely, so as to afford easy exit for the suppuration.

My colleague and friend, Dr. Lagrange, now made an ophthalmoscopic examination, and found the fundus normal without the slightest trace of paralysis of 
accommodation. For the moment one thought that the felrile state might be attriluted to the infection of the wound, and at the instance of the parents, while against it, I consented to postpone for three days any further intervention. This examination had taken place on a Sunday, and the practitioner in attendance came to me on the following Thursday stating that for the last forty-eight hours the condition of the child had got consilerably worse. The thermometer scarcely ever as scended below $393^{\circ}$, and the attacks became more numerous. The little patient, who up till now had been lively, and had played about on his bed, was depressed and answered less readily to question:. I proposed then the carrying out of the intervention of which $I$ had spoken, namely, making an opening through the skull into the cerebral fossa, and if nothing was found at this level then exploring the sinus, which I suspected as being the seat of the chief cause of the trouble. In view of the aggravation of the symptoms the family consented, and the operation was carried out on the Friday morning with the assistance of Prof. Piéchaud. The child having been put under chloroform, and the wound widely opened, I immediately attacked the osseous wall and exposed the meninges in the cerebral fossa. These appeared to be absolutely healthy, although the superficial veins were slightly congested.

Before advancing more deeply in this direction I attacked the wall of the sinus with the full conviction that it was there that I should find the origin of the in. fectious phenomena characterized solely by the thermometrical tracing which we had before us. Even at this time we had no external sign of phlebitis or of thrombosis; not the slightest rigidity of the neck, nor any lesion along the line of the jugular vein ; in a word, no other symptoms but the intense fever. The bone was extremely thick, it bled very freely and abundantly-to such a degree that 1 was considerably obstructed by the flow of blool during the whole operation, hemorrhage taking place at each touch of the gouge, just as if the sinus had been opened. Meanwhile, I succeeded in clearing away the osseous tissue, and opening the cranial cavity at the level of the sinus. Scarcely had I broken through the partition which separated me from the dura mater when a flow of pus took place. I enlarged the orifice, and the pus continued to lubble out just as blood coming from the sinus would have done; in fact, it spurted just as if there had been a large artery behind the pouch of the alscess. Little by little it emptied itself, and with all the greater facility as I enlarged still further the opening in the cranium, The liackish hemorrhage which had accompanied the exit of pus at the beginning soon ceased of itself, and I was then able to make out that the pus issued not from the wall of the sinus, but from the interior of its cavity. We were in the presence of a suppurative phlebitis which, in view of the lateness of the intervention, rendered the prognosis very grave in spite of the opening of the abscess. I placel several threads of catgut to act as a drain in the interior of the cavity of the sinus, and plugged the wound with iodoform gauze, leaving room for free drainage, so as to make sure of the easy exit of any discharge, and to allow of antiseptic irrigation being carried out. Unfortunately, the general state of the child was at this moment so bad, and the infection so severe, that death took place thirty-six hours later.

This third case is interesting on account of the course of the disease, which was characterized by the absence of any symptom pointing to a sinusal complication of otitic origin, except the temperature chart, which was sufficiently characteristic of an infective process, and which alone led me to think of a lesion of the kind and to propose at once the addition of surgical measures. Unfortunately, it is not always easy to induce the family to admit of an operation which may be dangerous and is often 
thought to be useless, because it is impossible to affirm, absolutely, the certainty of one's diagnosis, and, consequently, to hold out convincing hopes that the intersention may be of benefit to the patient. On the other hand, we must not be surprised at the want of success of our operative intervention in these cases, because pyamia of sinusal origin may be justly considered one of the gravest complications of chronic of acute suppurative inflammation of the middle ear.

I shall not dwell upon the interest of this case from the point of vic: of the course of the symptoms, the suppuration having subsided, subsequently, to such an extent that the membrane had cicatrized completely, but with a collection of pus and granulations behind the cicatrix which worked their way into the interior of the cranial cavity, instead of discharging outwardly and drawing the attention of the medical attendant.

There is no doubt that, if at the time of my previous visit, instead of a simple red bulging of the tympanic membrane, I had found a purticnt discharge, I would have operated on the mastoid process, and thus gained forty-eight hours, though possibly it might not have becn sufficient to cnable me to save the patient's life, in view of the difficultics offered by the family and the medical attendant, who would have opposed my interfering before the general symptoms were too far advanced for operation to bring about a goot result.

In this third case we have an illustration of complications of the sinus, different from each other, which manifested themselves simply by the pyrexia, more especially in the first and third cases. In the first case the abscess was extradural, but in the third, on the other hand, it developed in the interior of the sinus and aftected the entire circulation. As 1 said at the commencement of my remarks, these cases are sufiiciently rare among us to justify their narration in detail when one has the opportunity of observing them, whatever may be the final result of operative interference. These cases confirm the important point insisted upon by M. Broca, after Wheeler, at the time of his last communication to the Society of Surgeons, namely, that in presence of intracranial complications of otitic origin, we must commence with the ear, allowing ourselves to be suided by the lesions we mect inwards to the interior of the brain. An operation thus carried out is easy and simple, and it i, possible to enlarge the opening made in the sliull to whatever cxtent we wish, so as to examine either the sinus or the meninges of the cerebral fossa, or even to puncture the interior of the brain in various directions so as to make sure that there is no pus. In resard to this point I will recall a slight inciclent to which M. Lannois drew our attention last year, namely, the clossing of the interior of the hollow ncedle by cercbral matter during the search for ph. I think it is most necessary in these cetses to use a fine trocar and to practise slight aspiration, with perfectly aseptic instruments, as, of course, goes without saying. Further, before opening the lateral sinus in a doubtful case, it is, wise to make a capillary puncture with aspiration to see whether the channel contains blood or pus, or whether, on the contrary, it is thrombosed and ought to be laid open and cleaned, with or without previous lirgature of the jugular rein as the nature of the rase may lemand. 